\title{
Leser-Trélat syndrome associated with cancer larynx : A case report
}

\author{
Mohammed Elrabie Ahmed ${ }^{1}$, Mona Elrabie Ahmed ${ }^{1}$, Hesham Mostafa Abdelfattah ${ }^{2}$, \\ Mohammed Abu El-Hamd ${ }^{3}$, Wael Hassan Amr ${ }^{4}$
}

Case

${ }^{1}$ Phoniatrics, Otorhinolaryngology-Head and Neck Surgery Department, Sohag University, Report Sohag, Egypt

${ }^{2}$ Otorhinolaryngology-Head and Neck Surgery Department, University of Alexandria, Alexandria, Egypt

${ }^{3}$ Dermatology, Venereology and Andrology Department, Faculty of Medicine, Sohag University

${ }^{4}$ Surgery Department, Sohag Cancer Center, Sohag, Egypt

\begin{abstract}
Leser-Trélat syndrome (LTS) is a rare cutaneous paraneoplastic syndrome that barely affects patients with head and neck cancer. Here we present a case of 58-years old male presented with skin manifestation consistent with a sign of Leser-Trélat. A close investigation of the patient revealed that he had a recurrent laryngeal squamous cell carcinoma. The described case is the fifth case of a Leser-Trélat syndrome with squamous cell carcinoma of the larynx and the sixth to be reported in the head and neck squamous cell carcinoma. Thus sudden development of paraneoplastic dermatoses is recurrently a forewarning progression of the malignancy.
\end{abstract}

Key Words: Cancer larynx, head and neck cancer, Leser-Trélat syndrome, paraneoplastic syndrome

Corresponding Author: Mona Elrabie Ahmed, M.D., Department of Phoniatrics, Otorhinolaryngology-Head and Neck Surgery, Sohag University, Sohag, Egypt, Tel.: +1-873-200-4187, E-mail: daimahmoud@yahoo.com

ISSN: 2090-0740, March 2018 Vol.19, No.1

\section{INTRODUCTION}

Leser-Trélat syndrome (LTS) is a rare paraneoplastic phenomenon characterized by an abrupt appearance or acceleration of Seborrhoeic keratosis (SKs) that rapidly increase in size and number in association with an underlying internal malignancy ${ }^{[1]}$. The actual cause of LTS is unidentified, thought to be associated with tumorsecreting growth factors including epidermal growth factor, transforming growth factor-alpha, insulin like growth factor and immune-reactive human growth hormone, which can stimulate the epidermal growth factor receptor (EGFR). ${ }^{[2,3]}$ It primarily affects trunk (76\%) and lesser extent extremities $(38 \%)$. It may concur with the diagnosis of occult cancer $(9.6 \%)$ or after $(22.1 \%)$, or precede it within a year's $(68.3 \%)^{[4]}$. We present a case in which LTS had preceded the diagnosis of laryngeal squamous cell carcinoma (SCC) recurrence and associated with the development of a second primary in hypopharynx.

\section{2-Case report:}

In January 2011, a 56-year-old male patient, heavysmoker, presented with 3-months history of progressive dysphonia to Otorhinolaryngology Department, Sohag University, Egypt, for endoscopic larynx examination. Fiberoptic laryngeal exam revealed an exophytic mass affecting the whole length of the right vocal fold extended to involve about anterior third of the left vocal fold. Both vocal folds were freely mobile. Neck examination was free and there was no significant medical and family history. Moderately well differentiated squamous cell carcinoma (SCC) was diagnosed from the biopsy specimen. Full metastatic work up, including Computed tomography scan of the neck and chest and abdominal ultrasound confirmed a T1bN0M0 stage, according to the 7th edition of AJCC Cancer Staging Manual. After completion of the staging investigation radiotherapy was started using a localized field at a dose of 66 Gy which was completed, uninterrupted. Through first year follow up, the patient larynx was clear of any masses.

Thereafter, the patient did not show up until June 2013, He presented with progressively worsening dysphonia, followed by mild to moderate stridor for approximately three months. Several months before recurred of dysphonia, he had noted the sudden appearance of multiple brownishgray skin lesions in the face, neck, chest, both maxillae, 
and upper arms which were rapidly increasing in number and size. A dermatological consultant confirmed the presence of multiple seborrheic keratosis (mSKs) (Fig 1A). Tracheotomy was performed under local anesthesia before direct laryngoscopy. The laryngoscopic examination revealed multiple right transglottic exophytic mass involving the ipsilateral medial aryepiglottic, ventricular fold, the right pharyengo-epiglotic fold, contralateral left supraglottic region with multiple nodules in the lateral wall of the right pyriform fossa with immobile right vocal fold and edematous curled epiglottis as shown in (Fig 1B).

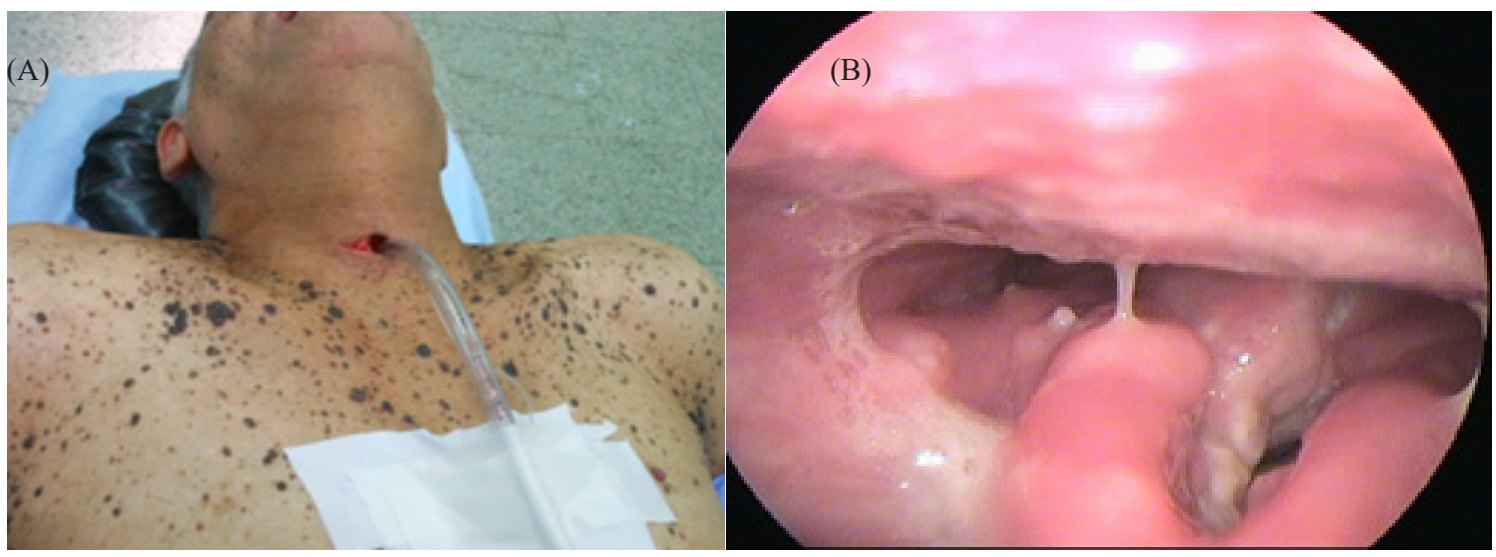

Fig 1: (A) Show multiple brownish-gray skin lesions (multiple seborrheic keratosis) in neck, chest, both maxillae, and upper arms. (B) Laryngoscopic examinations show right trans-glottic exophytic mass involving aryepiglottic, ventricular fold, pharyengo-epiglotic fold, with multiple nodules in the lateral wall of the right pyriform fossa and edematous curled epiglottis.

Histological examination revealed a moderately well differentiated SCC. One month later; the preoperative laryngoscopic examination had been done. Neck computed tomography showed right transglottic mass with no cartilage invasion and bilateral lymph node at level II and III (Fig.2).

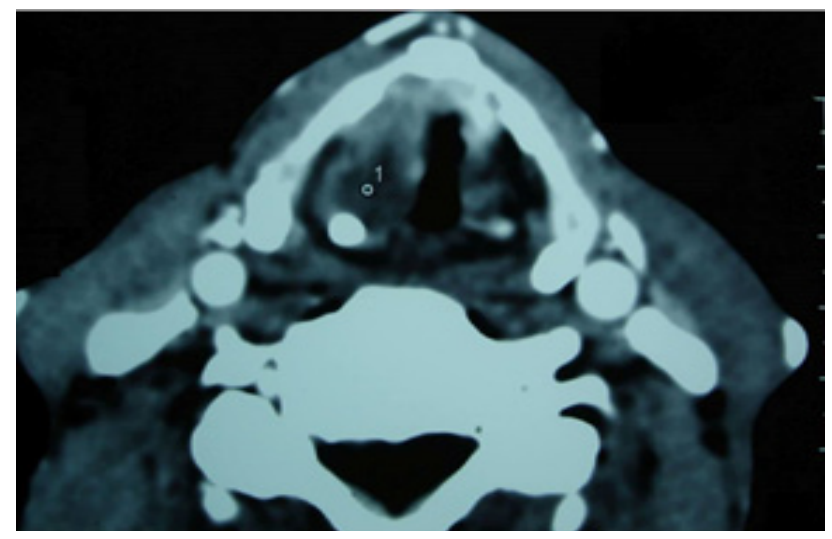

Fig 2: Preoperative axial CT shows right trans-glottic mass.

Chest and abdominal computed tomography revealed no abnormalities. Metastatic work up revealed T3N2cM0 staging. Total laryngectomy and right partial pharyngectomy with bilateral functional neck dissection were done. The operation started with smooth induction and stable monitoring parameter. During recovery, the patient developed progressive bradycardia, hypotension non responsive to inotropes ended by cardiac resuscitation. According to the anesthetic team, all features pointed that patient died due to pulmonary embolism. Histopathological diagnosis was compatible with moderately well differentiated SCC with no extra-laryngeal spread (Fig.3). There was normal mucosa between the index tumor and the lateral wall of right pyriform sinus tumor.

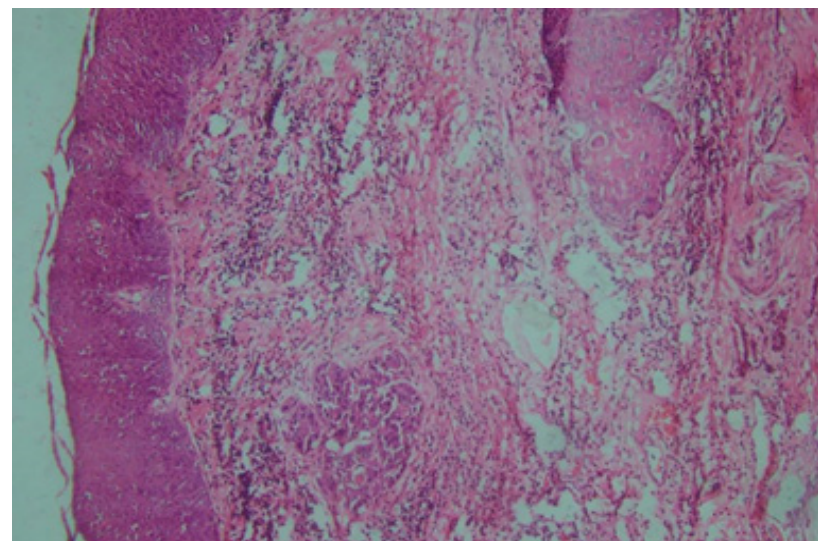

Fig 3: Histopathological examination shows a moderately well differentiated Squamous Cell Carcinoma (Hematoxylin and Eosin stain x 200).

\section{DISCUSSION:}

The commonest associated malignancy with SLT is gastrointestinal adenocarcinomas and lymphoproliferative disorders ${ }^{[2,5]}$. Only five cases of LTS in head and neck have been reported in literature (Table 1) with four cases of SCC of the larynx and one of the nasopharyngx ${ }^{[6-9]}$. Thus, the current case is the fifth case of LTS with laryngeal SCC and sixth in head and neck SCC. It was associated with relapse and a synchronous pharyngeal second primary malignancy after previous radiotherapy treatment. LTS is not widely 
accepted as a paraneoplastic syndrome because SKs and cancers increase in incidence parallel with aging, making a higher likelihood of coincidence. While the evidence favoring a link between LTS and underlying malignancy includes sudden mSKs eruption and the high rate of its coexistence with other well-recognized paraneoplastic conditions in $>110$ reports. In addition, LTS was reported in young patients in their 20 s with osteogenic sarcoma and germinoma of the pineal body, both unlikely to have mSKs, shows the validity of this $\operatorname{sign}^{[1]}$. It needs a prompt thorough diagnostic workup for an underlying malignancy or a recurrence of a pre-existing one ${ }^{[8]}$. In current case, patient had a sudden onset rapidly progressive skin changes preceded his rapid deterioration suggesting that this is a paraneoplastic dermatosis. That highlights the importance of early recognition of these cutaneous hallmarks which offers an opportunity for monitoring for tumor recurrence.

Actually, it turned into more common in the medical literature, the association of some dermatoses with visceral neoplasms ${ }^{[4]}$. Knowledge of these dermatoses is of paramount importance, since they behave as a tumor marker, and may many sometimes precede the onset of the disease, and possible recurrence of the same. Especially, LTS is an ominous sign suggesting highly aggressive advanced tumor, 57\% metastatic spread incidence and a poor prognosis. Actually, the prognosis of patient with LTS includes improvement (48\%), recurrence $(9.7 \%)$, exacerbation new malignancy $(4.8 \%)$, and death $(37 \%)$. The average survival rate is 10.6 months after the appearance of mSK ${ }^{[3-4]}$. LTS may be a useful indication for the examination of tumor EGFR expression and subsequent EGFR inhibitors treatment (cetuximab) of these patients with high levels of tumor EGFR, to improve the survival ${ }^{[10]}$

\section{CONCLUSION AND RECOMMENDATIONS}

The sudden development of paraneoplastic dermatoses is recurrently a forewarning progression of the malignancy. Cautiously, patients with LTS need a careful intraoperative monitoring and thromboprophylaxis measures.

LTS gains greatest diagnostic and prognostic importance. Nonetheless, it has neither gained the proper interest nor mentioned in the classification of paraneoplastic syndromes associated with head and neck cancer. Thus, we recommend considering LTS in the classification of the cutaneous paraneoplastic manifestation in head and neck cancer.

\section{CONFLICT OF INTEREST}

There are no conflict of interest.

\section{REFERENCES}

1. Berlin, C., Li, L., and Hood, L. (2002): Auditory Neuropathy/Dys-Synchrony: After the Diagnosis, then what? Seminars in Hearing, 23, 3: 209-214.

2. Berlin, C. Hood1, L., Morlet, T. Wilensky, D., et al., (2010): Multi-site diagnosis and management of 260 patients with Auditory Neuropathy/Dyssynchrony (Auditory Neuropathy Spectrum Disorder). International Journal of Audiology. 49: 30-43.

3. Beutner, D., Foerst, A., Lang, R., Roth, H. and Walger, M. (2007): Risk factors for auditory neuropathy/auditory synaptopathy. Otorhinolaryngol, 69: 239-244.

4. Bielecki I, Horbulewicz A, Wolan T. (2012): Prevalence and risk factors for auditory neuropathy spectrum disorder in a screened newborn population at risk for hearing loss. Int J Pediatr Otorhinolaryngol 76: $1668-70$.

5. Ferguson, S. (2012): Vowel intelligibility in clear and conversational speech for normal-hearing and hearingimpaired listeners. Journal of the Acoustical Society of America, 112: 259-271.

6. Rubisz-Brzezińska J, Zebracka T, Musiałowicz D. [Coexistence of 2 paraneoplastic syndromesacrokeratosisbazex and Leser-Trelat syndromein a case of squamous-cell laryngeal cancer]. Przegladdermatologiczny. 1982; 70:205-208.

7. Kawase Y, Mizobuchi N, Hayashida Y,Sakakibara N.A case of double cancer of the stomach and larynx with the sign of leser-trélat. The journal of the Japanese Practical Surgeon Society. 1994; 55:2410-2414.

8. Li M, Yang LJ, Zhu XH, Zhang YS, Sun H, Jiang PD, Zhang RR, Tang W, Cai Y. The Leser-Trélatsign is associated with nasopharyngeal carcinoma: case report and review of cases reported in China. Clinical and experimental dermatology. 2009; 34:52-54.

9. Nyati A, Kalwaniya S, Jain S,Soni B. Sign of LeserTrélat in association with laryngeal carcinoma. Indian Journal of Dermatology, Venereology, and Leprology. 2016 1; 82(1):112.

10. Jepsen RK, Skov AG, Skov BG. Leser-Trélat syndrome in malignant mesothelioma and pulmonary adenocarcinoma: is the EGFR pathway part of the syndrome? Virchows Archiv. 2014; 464:117-120. 